\title{
Optimizing the User Environment: Leading Towards an Accessible and Usable Experience
}

\author{
Jatinder Dhiensa, Dr Colin Machin, Francesca Smith, Dr Roger Stone \\ Research School of Informatics, \\ Loughborough University, Leicestershire, UK. \\ J.Dhiensa@Iboro.ac.uk
}

\begin{abstract}
Although standards and legislation such as Web Content Accessibility Guidelines 1.0 and the Disability Discrimination Act 1995 have come into place, the inaccessibility of web content still exists. This paper presents the Essentiality and Proficiency Tool. The tool is a proxy service that will enable the user to view web content in accordance with their individual needs. A prototype has been developed and tested, highlighting insights into user patterns. The paper will explore the importance of universal design in making the Internet more accessible. It will further explore how user profiles endorse universal design, leading to a more usable experience. Although the emphasis is on a universal tool we start by concentrating on users with visual impairments as this is identified as the largest disability group.
\end{abstract}

Disability, Inaccessibility, Universal Design, User Profiling

\section{INTRODUCTION}

Research has shown that even though WCAG 1.0 goes a long way to ensuring accessibility, the Web still presents a usability issue. The problem is three-fold. Firstly there is the issue of 'information exclusion'.[1, 2, 3]. Secondly even though the standards and legislation exist and measures are being taken to meet the requirements, this does not necessarily ensure usability [4]. The sheer volume of information contained in pages is found to be overwhelming. Finally there is a lack of awareness of universal design in the development of web pages and has in the past lead to the development of many versions of one site $[5,6]$.

\subsection{Possible Solutions}

There have been many attempts to address the issue of making web content more accessible $[6,7,8,9,10,11$, 12,13]. The Web Adaptation Technology is a prime example that offers users with varying disabilities the ability to customise the visual interface to meet their needs [8]. Users are given various options by which they can alter the interface. They can enlarge the content of the page, adjust the font, reduce the distractions on the page etc. The Web Adaptation Technology allows the user to change the visual content 'on the fly'. The key to this technology is that it adapts content returned from HTTP requests and thus the visual adaptation appears exclusively for the user and the page source is left unchanged [8]. Another example is WebClipping2 which incorporates a content-based filtering coupled with user profiles strategy to extract news articles that are of interest to the user in accordance to their profile [14].

\section{THE ESSENTIALITY AND PROFICIENCY TOOL}

As a solution we present the Essentiality and Proficiency tool which addresses the issue of inaccessibility due to the overwhelming amount of information. In any collection of information - for a web page or otherwise, some data is more important than others. By rating web content on how essential it is to convey the meaning of the site we can develop a method for restricting the volume of content that is fed through and displayed on to a web page.

The Internet is almost entirely a visual experience therefore it is important that visually-impaired users are able to access the same information easily and in the most suitable format for their needs just as it is displayed for all others. The key to easier navigation and usability for the visually-impaired is the volume of information on the page in front of them. The Essentiality and Proficiency Tool offers the user the choice of selecting their own formatting preferences and level of essentiality or of opting for a user profile according to the severity of their impairment. The latter sets default values for the variables that can be manipulated subsequently. It is believed that through the use of this tool the web will be made easier to utilise for all user types and will become more accessible to those with disabilities.

The advantage of a tool such as this is that it is generic for all user types, not just those with a visual disability. This means that a visually-impaired user will be making use of a tool created for all, as opposed to it being created 
just for their needs, which can perhaps make them feel included rather than excluded. The latter is the case when companies create alternative versions of their sites (usually text only) for those less able. In this instance all users still utilise the same URL for each site, however the content of the page is manipulated to suit their informational needs.

For a visually-impaired user this means they can limit the textual information or images displayed on the page according to their needs. This is where the user profiles come into play. There are a huge variety of eye conditions varying in severity from cataracts and nystgamus to almost complete depletion of sight. Each of these conditions has a different set of information and presentation requirements when it comes to using the web. Through the collection of user preferences such as font size, font colour, background colour and text style across a range of visual conditions, profiles for each condition can be created preventing the user having to fill in a form which may be time consuming. Furthermore they can set an essentiality rating of information based on how much time they have to browse the Internet or simply based on how much information they can cope with on a page.

\subsection{Process Breakdown}

The Essentiality and Proficiency tool is a proxy service that will enable users to pick a user profile (see Table 1). The user profile is based on user requirements that have been gathered from the user requirements survey. This differs from WebClipping2 as its profiles are based on the system monitoring reading behaviours [14]. The user will be able to view content of a web page in accordance with their needs.

TABLE 1: Process Breakdown for Essentiality and Proficiency Tool

\begin{tabular}{|c|l|l|}
\hline Author & Marking & Author marks up essential content. \\
\hline User & Defining & To allow the user to choose a profile description that best suits their requirements. \\
\hline & Requesting & To allow the user to request a URL. \\
\hline Server & Capturing & To capture the contents of the web site. \\
\hline & Processing & To process web content through the essentiality and proficiency filter. \\
\hline & Rendering & To display the information. \\
\hline
\end{tabular}

\subsubsection{Essentiality}

On any given web page, there may be some information which is of more use than others. Websites are often found to contain very little information that is essential. In other words, the meaning of the site can be portrayed in a very small amount of information. Some elements of the page may have a high information level making it essential for this to be displayed, but other elements are purely aesthetic (such as images) and can be cumbersome for those who have little time and/or bandwidth.

For example imagine if a user was organising a business trip and needed to look up a hotel and required only the most essential information such as location and room rates to be displayed. If the user could set an essentiality level on a website, they could retrieve information faster, easier and have the ability to set an essentiality rating based on how much time they have to surf the web. For visually-impaired users who operate screen readers, this will mean a reduced need to trail through vast amounts of unessential information.

The essentiality has a two-fold purpose (see Figure 1). Firstly it refers to the author's mark-up in accordance to what they identify as most essential for the user, when conveying information through their website. The essentiality will be measured as a level from 1-10, Level 1 starts with include everything and Level 10 only includes the most essential information. Secondly, the essentiality also encapsulates the needs of the user through the user profiles. Although the Web Adaptation technology also transforms web content to the user's needs it does not enable the user to view only the essential information. Furthermore, as stated earlier, all the transformation takes place upon transmission to the user and the actual source is left untouched. However for the essentiality factor of our tool the source code will have to be altered by the author to include essentiality tags. 


\begin{tabular}{|l|l|}
\hline User Essentiality & Author Essentiality \\
Dependent on User requirements \\
in terms of the information type and \\
the amount of: \\
$\begin{array}{l}\text { - Text } \\
\text { - Audio } \\
\text { - Visual }\end{array}$
\end{tabular} \begin{tabular}{l} 
Most essential information to be \\
conveyed to user, in the form of: \\
- Text \\
- Audio \\
- Visual \\
\hline
\end{tabular}

FIGURE 1: Mapping of Essentiality Level

\subsubsection{Proficiency}

Proficiency defines the rendering capabilities of the device being used, e.g. whether it is a desktop PC, a laptop, a PDA or a mobile phone [15]. For example due to the size of the user interface on mobile phones and PDAs there is limited volume of content that can be displayed to the user. This leads to a measure of its "proficiency". The same logic can be applied to the ability of a given visually-impaired user to accept or perceive particular content or format. Different forms of visual-impairment impact on users in very different ways. For example, cataracts produce low-contrast vision, with associated loss of resolving power and sharpness. People suffering from glaucoma will see an image only in the central field of vision. The opposite is true of those with macular degeneration, where only the area surrounding the axis is visible. Those with symptoms of diabetic retinopathy have blotchy vision. As a result, it is possible to identify particular solutions to many of these forms of visionimpairment. In doing so, we have come up with a near-parallel solution to that of display or bandwidth limitations.

\subsection{A Possible Technical Solution}

The essentiality tags can be applied to the essential content of a simple, static page (A). However for a dynamic page (B), where the results returned are from user's search, perhaps the user may wish to choose a location on a travel site, there will be a need for a live calculation of essentiality.

User's -----URL

http://www.blahblah/

http://www.blahblah/?x=y=\&

In essence what the user may find essential one day may differ on the next. Hence this will be a two-stage development, where the essentiality of $(\mathrm{A})$ will be the prime focus before attempting to develop the tool towards a live calculation of essentiality for (B). The step from one to the other is not a huge one, as the process relies simply on filtering the http stream in search of particular tags.

\section{THE IMPORTANCE OF USER PROFILES}

The importance of generating a range of user profiles lies in the ability for a product to be accessible to a range of users rather than one specific group [16]. Although retro-fitting is constantly criticised by specialists, there is a need for it, as the Internet has been present for a number of years and is constantly developing in terms of audio, visual and graphics content and ability. Furthermore although accessibility standards, such as WCAG 1.0, have been taken up by a number of governments as part of their legislation, not all developers are developing accessible sites. The retro-fitting of these websites will take a number of years to ensure that they are all accessible.

In contrast, studies have shown that the severity of one's visual condition effects the time taken to complete simple tasks on the web [17]. Users were split into three groups. In the allocated time the control group of non disabled users completed $75 \%$ of the tasks, the low vision group completed $25 \%$ and the blind group completed $12.5 \%$. The results reflect the current poor state of design of web browser technology and web resources for those with disabilities. This study identifies that users with different levels of visual disability have different needs and abilities, thus the need to create profiles for categories of these diseases.

This leads to the importance of the Proficiency and Essentiality tool so that users can access the sites. To cater for the needs and requirements of a larger user base, the tool will have a number of preset user profiles that have been developed from the survey carried out to the capture user requirements. 


\section{USER REQUIREMENTS SURVEY}

As part of our preliminary research we conducted a survey to gather user requirements from visually-impaired users for the Essentiality and Proficiency tool. The aim was to find out what difficulties were being experienced and what measures could be taken to make navigation of a web page easier. The data was required from different visual impairments to build up profiles through the collection of formatting preferences such as font styles, colour schemes etc.

The survey consisted of one-to-one interviews with twelve participants from RNIB College and questionnaires that were sent out to various mailing lists. The RNIB College is a vocational college which enabled us to survey people of different ages with a broad range of visual impairments. The mailing lists were technology-orientated and therefore we were able to gather information from users with a variety of user experience.

The interviews highlighted the improvements the Internet had brought to the lives of users with visual impairments (see Case Study 1). However it also brought to light the limitations that deter some users from using the Web (see Case Study 2).

\section{Case Study 1}

Mick is a 54 year-old web developer with no useful sight. Until 1995 he was unemployed and housebound. His daily lifestyle included doing household chores and once a week he attended a drop-in centre for the disabled. During 1995 Mick was introduced to IT with aid of assistive technology in the form of a screen reader (Jaws). Mick learned new skills and gained an independence that he didn't think was possible.

With the aid of the screen reading software, Mick has gained vast experience in IT. Mick now develops web sites, checks other sites for accessibility and also teaches other visually-impaired students.

Although Mick has made these strides forward, it does not mean that he is being served as best as he could with his assistive technology. For example, the inaccessibility of some websites leads to the screen reader vocalising all the link information.

\section{Case Study 2}

Alice (49) is a secretary and has no useful sight. Alice is proficient in the use of IT. Using a screen reader Alice creates spreadsheets, word documents and regularly checks and sends emails as part of her work. However Alice avoids using the Internet due to the confusion and the visual clutter she experiences. Alice dislikes having to read vast amounts of information as she feels overwhelmed before she even reaches the part that she needs.

Case Study 2 reveals that even though online technologies have been developed to increase social inclusion, they are failing due to their inaccessible nature. Case Study 2 highlights how the sheer volume of content deters Alice from using the Web.

There were 38 replies to the questionnaire survey, showing that:

$42 \%$ of the respondents admit that their primary difficulty in using the Web was the overload of information on a page. The second highest difficulty was visual clutter at $23 \%$. These figures suggest that there are a significant number of visually-impaired Internet users who find it difficult to navigate the Web as there is too much content on a page and the information becomes hard to digest. (This was also evident in Case Study 2.) $69 \%$ of those questioned said it would be useful or very useful to be able to manipulate the volume of information on a web page, and $77 \%$ agreed that reducing the amount of information displayed on a page according to the essentiality would ease their use of the Internet. This translates into a significant proportion of respondents in favour of the essentiality element of the tool.

\section{USER PROFILES IN PRACTICE}

Table 2 shows an example of the different user groups within the field of visual impairment. Taking these as a first set of profiles we narrowed down the requirements from the survey to create more intensive profiles (Figure 2) for the prototype. 
TABLE 2: Visually-impaired User Profiles

\begin{tabular}{|l|l|l|}
\hline User Profile & $\begin{array}{l}\text { Strength of Visual } \\
\text { Impairment }\end{array}$ & Assistive Technology \\
\hline 1 & Partially Sighted & $\begin{array}{l}\text { Large font } \\
\text { Different background }\end{array}$ \\
\hline 2 & Mild/Moderate vision & Screen magnification software \\
\hline 3 & No vision & $\begin{array}{l}\text { Screen readers } \\
\text { Refreshable Braille displays }\end{array}$ \\
\hline
\end{tabular}

\begin{tabular}{|c|c|}
\hline User Profile 1 Overview & Profile parameters \\
\hline $\begin{array}{l}>\text { User has a slight visual impairment } \\
\text { Changes formatting preferences in the } \\
\text { browser } \\
>\text { Frequent user of the Internet } \\
>\text { Finds that there is too much information } \\
\text { on a page }\end{array}$ & $\begin{array}{l}>\text { Black text on a pastel background } \\
>\quad \text { Font size } 14 \text {, font style Arial } \\
>\quad 1-2 \text { images can be meaningful } \\
>\quad \text { Essentiality level } 4-5\end{array}$ \\
\hline User Profile 2 & \\
\hline $\begin{array}{l}>\text { Mild visual impairment } \\
>\text { Has difficulties with font size } \\
>\text { Screen magnification user } \\
>\text { Uses Internet once a week } \\
>\text { Difficulty understanding images when } \\
\text { using desired setting of screen } \\
\text { magnification }\end{array}$ & $\begin{array}{l}>\text { Large font size } \\
\text { Only essential images } \\
>\text { White text on black } \\
>\text { Font style Arial } \\
>\text { Essentiality level 5-6 }\end{array}$ \\
\hline User Profile 3 & \\
\hline $\begin{array}{ll} & \text { No useful vision } \\
& \text { Screen reading software user } \\
> & \text { Frequent user of the Internet } \\
& \text { Would prefer no images, as incorrectly/ } \\
& \text { unlabelled images are useless } \\
> & \text { Flash incompatible with JAWS }\end{array}$ & $\begin{array}{ll}> & \text { No images } \\
> & \text { Text size compatible with JAWS } \\
> & \text { Black on yellow } \\
> & \text { Essentiality level 7-8 }\end{array}$ \\
\hline
\end{tabular}

FIGURE 2: User profiles from real users

\subsection{User Trials}

The user testing of the prototype was limited to four participants. We requested participants from the initial user requirements survey to test the tool as it would better validate the work. The group represented a range of ages, gender and visual impairments. The prime purpose of this testing was to see if the users would choose the user profile that had been created based on the level of visual impairment that they have.

The participants were given four quite different renderings (Figure 3) of Quaglino's web page for them to browse through using their respective assistive technologies. This is a web site promoting a restaurant in the heart of London and represents a mixture of graphics and text in different styles. Five minutes of browsing was allowed per page. Once the participants had seen all four pages they were questioned.

Figure 4 show that each user had very different requirements, which may change over a period of time. One participant explained how they needed to change the font size after looking at the screen for a short period, as their eyes become tired and it becomes harder to view the content. Furthermore the preferences identified by the participants at the interviews had changed at the testing stage. Hence it appears that the participants would like the option to manipulate format as different factors affect the user requirements. 


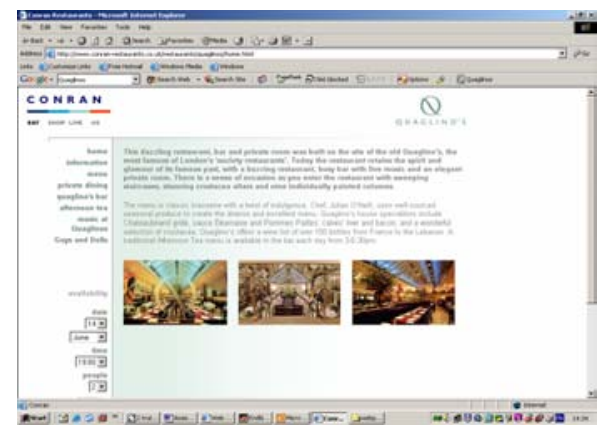

Quaglino's original web page

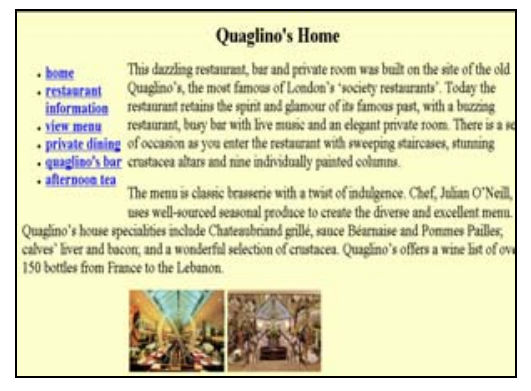

User Profile 1

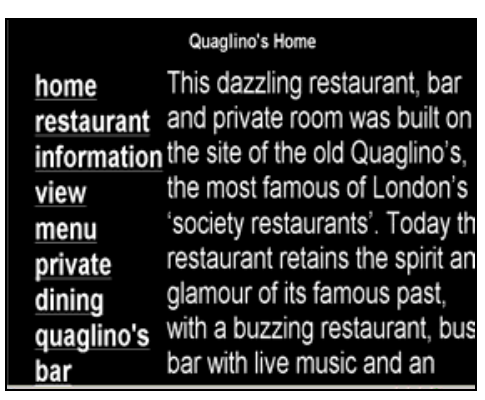

User Profile 2

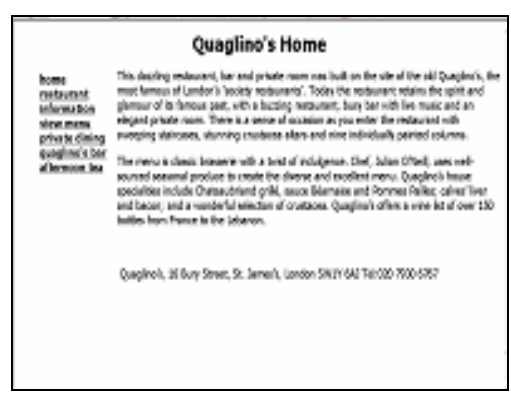

User Profile 3

FIGURE 3 Quaglino's original web page altered to each of the three sample profiles

FIGURE 4 Test Results

\begin{tabular}{|c|c|c|c|c|}
\hline & Participant 1 & Participant 2 & Participant 3 & Participant 4 \\
\hline Intended profile & Profile 3 & Profile 1 & Profile 2 & Profile 1 \\
\hline Preferred profile & Profile 3 & Profile 3 & Profile 1 & Profile 1 \\
\hline $\begin{array}{l}\text { Assistive } \\
\text { technology used }\end{array}$ & Screen reader & $\begin{array}{l}\text { Enlarging the text } \\
\text { in operating } \\
\text { systems settings }\end{array}$ & $\begin{array}{l}\text { Screen } \\
\text { Magnification }\end{array}$ & $\begin{array}{l}\text { Screen } \\
\text { Magnification }\end{array}$ \\
\hline $\begin{array}{l}\text { Differences } \\
\text { apparent } \\
\text { between the } \\
\text { pages }\end{array}$ & $\begin{array}{l}\text { Less text } \\
\text { Information easily } \\
\text { found }\end{array}$ & $\begin{array}{l}\text { Less information } \\
\text { displayed } \\
\text { Colour change } \\
\text { Fewer images }\end{array}$ & $\begin{array}{l}\text { Less information } \\
\text { Change in colour } \\
\text { scheme }\end{array}$ & $\begin{array}{l}\text { Less content } \\
\text { Greater colour- } \\
\text { contrast on } \\
\text { Profile } 2 \\
\text { Profile } 3 \text { is text } \\
\text { only }\end{array}$ \\
\hline $\begin{array}{l}\text { Reasons for } \\
\text { preferred site }\end{array}$ & $\begin{array}{l}\text { Likes the amount } \\
\text { of text on the } \\
\text { Profile } 3 \text { but } \\
\text { would also like } \\
\text { images that could } \\
\text { be enlarged as } \\
\text { has some } \\
\text { available sight }\end{array}$ & $\begin{array}{l}\text { Very clear and } \\
\text { concise } \\
\text { Comfortable to } \\
\text { read }\end{array}$ & $\begin{array}{l}\text { Text is easy to } \\
\text { read } \\
\text { Profile } 3 \text { would } \\
\text { strain eyes and } \\
\text { text not bold } \\
\text { enough }\end{array}$ & $\begin{array}{l}\text { Good contrast } \\
\text { balance } \\
\text { Suitable amount } \\
\text { of information }\end{array}$ \\
\hline Other comments & $\begin{array}{l}\text { As long as the } \\
\text { text is read by the } \\
\text { screen reader } \\
\text { have no text size } \\
\text { preferences }\end{array}$ & $\begin{array}{l}\text { As time elapses, } \\
\text { text size has to } \\
\text { be increased as } \\
\text { eyes become } \\
\text { tired }\end{array}$ & $\begin{array}{l}\text { Would like the } \\
\text { ability to enlarge } \\
\text { the images }\end{array}$ & $\begin{array}{l}\text { Would like to } \\
\text { enlarge both the } \\
\text { images and text }\end{array}$ \\
\hline
\end{tabular}




\section{CONCLUSION}

In conclusion, we have presented findings from our preliminary survey that has highlighted a three-fold problem of 'information exclusion', the lack of awareness of universal design in the development of the Internet and websites and the inaccessibility still experienced by real users even though standards and legislation have come in to place. A solution has been presented in the form of the Essentiality and Proficiency tool which incorporates user profiles to increase accessibility and usability of websites. The Essentiality and Proficiency tool has also been considered in contrast to other possible solutions. User profiling has been discussed as a means of incorporating universal design into increasing accessibility of information from the Internet.

\section{FURTHER WORK}

The Essentiality and Proficiency prototype, when developed applied user preferences client side but now we are trying to build the system that works server side, this is to ensure cross browser compatibility. The system will take into consideration important factors highlighted by the testing of the prototype. Once the tool has been developed it will again be tested by a range of visually impaired users.

\section{REFERENCES}

[1] Christie, I. and Mensah-Coker, G. (1999) An Inclusive Future? Disability, social change and greater opportunities for greater inclusion by 2010 , London, DEMOS.

[2] Ross, M. (2002) Quality in Web Design for Visually Impaired Users. Software Quality Control 10(4) 285 - 298.

[3] Wattenberg, T. (2004) Beyond Standards: Reaching Usability Goals Through User Participation. ACM SIGACCESS Accessibility and Computing, 79, 10 - 20.

[4] Hudson, W. (2004) Inclusive design: accessibility guidelines only part of the picture. Interactions, 11, 55 - 56.

[5] Clarkson, J., Coleman, R., et al. (2003) Inclusive Design: Design for the whole population. Springer, London.

[6] Kottapally, K., Ngo, C., et al. (2003) Towards the Creation of Accessibility Agents for Non-visual Navigation of the Web. ACM Conference on Universal Usability, Vancouver, Canada. ACM Press.

[7] AccessIT (2004) How does accessibility differ across operating systems? University of Washington, Washington.

[8] Hanson, V. L. (2004) The User Experience: Designs and Adaptations. International Cross-disciplinary Workshop on Web Accessibility, World Wide Web Conference (WWW2004). ACM, New York City, USA.

[9] Lee, A. (2004) Scaffolding Visually Cluttered Web Pages to Facilitate Accessibility. AVI, ACM Press, Gallipoli, Italy.

[10] UMIST (2004) WebbIE. UMIST, Manchester.

[11] Brajnik, G., Cancila, D., et al. (2005) Do text transcoders improve usability for disabled users? Proceedings of the 2005 International Cross-Disciplinary Workshop on Web Accessibility (W4A) Chiba, Japan pp 9 - 17. ACM Press.

[12] Gupta, S. and Kaiser, G. (2005) Extracting content from accessible web pages. Proceedings of the 2005 International Cross-Disciplinary Workshop on Web Accessibility (W4A) Chiba, Japan pp 26 -30. ACM Press.

[13] Parmanto, B., Ferrydiansyah, R., et al. (2005) AcceSS: accessibility through simplification and summarization. Proceedings of the 2005 International Cross-Disciplinary Workshop on Web Accessibility (W4A) Chiba, Japan pp 18 - 25. ACM Press.

[14] Carreira, R., Crato, J. M., et al. (2004) Evaluating adaptive user profiles for news classification. International Conference on Intelligent User Interfaces, Funchal, Madeira, Portugal. ACM Press.

[15] Hook, T. E. (2003) Capability and Essentiality in Web Content. Department of Computer Science, Loughborough University, Loughborough.

[16] Sugiyama, K., Hatano, K., et al. (2004) Adaptive web search based on user profile constructed without any effort from users. 13th International Conference on World Wide Web, New York, USA. ACM Press. 
[17] Gunderson, J. (2004) W3C user agent accessibility guidelines 1.0 for graphical Web browsers. Universal Access in the Information Society 3(1), 38 - 47. 